\title{
Laterality and Accuracy of Force Exertion in Elbow Flexion
}

\author{
Hiroki Aoki ${ }^{*}$, Shinichi Demura² \\ ${ }^{1}$ National Institute of Technology, Fukui College, Fukui, Japan \\ ${ }^{2}$ Kanazawa University, Kanazawa, Japan \\ Email:^aoki@fukui-nct.ac.jp
}

How to cite this paper: Aoki, H., \& Demura, S. (2017). Laterality and Accuracy of Force Exertion in Elbow Flexion. Advances in Physical Education, 7, 101-106. https://doi.org/10.4236/ape.2017.71009

Received: July 10, 2016

Accepted: February 25, 2017

Published: February 28, 2017

Copyright (c) 2017 by authors and Scientific Research Publishing Inc. This work is licensed under the Creative Commons Attribution International License (CC BY 4.0).

http://creativecommons.org/licenses/by/4.0/

\begin{abstract}
In elbow flexion, accuracy of force exertion on demand values might differ between dominant and non-dominant hands. This study examined laterality and accuracy of force exertion in elbow flexion. The participants were 22 right-handed, healthy young males (mean age $22.6 \pm 4.3 \mathrm{yrs}$, mean height $172.7 \pm 7.0 \mathrm{~cm}$, mean mass $75.0 \pm 12.3 \mathrm{~kg}$ ). Demand values of $25 \%, 50 \%$, and $75 \%$ of maximum voluntary contraction (MVC) were selected. Using subjective judgment, the participants exerted the elbow flexion strength of each arm on each demand value. Evaluation parameters were differences (errors) between demand and exertion values and their total error. The results of a twoway ANOVA (dominant and non-dominant arms $\times$ demand value) showed significant interaction. In multiple comparison tests, errors were greater in $25 \%$ MVC than in 50\% and 75\% MVC for both arms. However, no significant difference was found between arms. In conclusion, in both dominant and non-dominant arms, accuracy of force exertion in elbow flexion does not show laterality and is higher in greater demand values (over 50\% MVC) than in lesser values (25\% MVC).
\end{abstract}

\section{Keywords}

Isometric Strength, Laterality, Accuracy

\section{Introduction}

So far, a few tests have been developed to evaluate accuracy in upper-limb force exertion. Kitabayashi et al. (2013) examined the accuracy of subjectively judged pinch-strength exertion on each demand value. Many researchers (Kubota and Demura, 2011; Kubota et al., 2012), including Nagasawa et al. (2013), have examined the ability to exert a handgrip coordinated with adjusting an index shown on a screen. These studies mainly targeted force exertions of a hand or 
fingers; errors between demand and exertion values have generally been used as an index of force exertion accuracy. On the other hand, according to Demura et al. (2012), upper-limb movements are divided roughly into two types according to related joints: one large joint (elbow flexion) and plural small joints (handgrip). The agonist muscle or muscular innervation ratio differs between elbow flexion and handgrip (Voss, 1971). In short, muscle groups participating in achievement of movement differ according to the body parts exerting strength. Hence, force exertion accuracy on each demand value might differ between elbow-flexion and handgrip movements.

Furthermore, each human body part with a bilateral symmetry shows a functional right and left difference called "laterality" (Dolcos et al., 2002; Bohannon, 2003; Roy et al., 2003; Noguchi et al., 2009). Laterality is found particularly in functions of fingers, for instance, using a spoon or writing letters, and results from preferential, frequent use of one hand in daily life activities. Kitabayashi et al. (2013) reported that an error between demand (50\% MVC) and exertion value in pinch strength was less in the dominant than in the non-dominant hand, and laterality was found in its accuracy. In addition, Seki and Ohtsuki (1995) reported that an error between demand and exertion values in force exertions of the upper limb (e.g., handgrip movement, the abduction movement of fingers, etc.) showed a little difference between dominant and non-dominant hands. In other words, laterality in accuracy of force exertion might differ according to the body parts exerting strength and the method of exertion, even in various movements of the same upper limb. In daily life, persons exert-while to some extent predicting-only the strength needed to achieve a movement, rather than exerting maximal strength. However, such force-exertion sense decreases with age (Yoshitake et al., 2011), and this decrease complicates the achievement of smooth and effective movements, thereby interfering with daily life activities. However, the accuracy of force exertion of sub-maximum elbow flexion and laterality has been scarcely examined.

Therefore, this study examined the accuracy of force exertion in elbow flexion on each demand value and laterality.

\section{Methods}

\section{1) Participants}

The participants were 22 healthy young males (mean age $22.6 \pm 4.3 \mathrm{yrs}$, mean height $172.7 \pm 7.0 \mathrm{~cm}$, mean mass $75.0 \pm 12.3 \mathrm{~kg}$ ). All were judged to be righthanded, based on Demura et al.'s (2009) dominant hand survey. We explained to participants the experimental purpose, methods, and risks and obtained their consent. The study protocol was approved by the Ethics Committee on Human Experimentation of the Faculty of Human Science, Kanazawa University (approval number: 2012-02).

2) Experimental Equipment and Methods

Each participant sat sideways on an adjustable chair and placed an axilla on the table's edge keeping the forearm supinated. After a participant touched his 
palm to the chair's handle, isometric strength exertion by elbow flexion (joint angle of 90 degrees) was measured. The participants performed the MVC test twice with both arms, and a higher value was used as the MVC. Demand values selected for force exertion tests were $25 \%, 50 \%$, and $75 \%$ of maximal elbow flexion strength based on a previous study (Seki and Ohtsuki, 1995).

Two trials, with a 2-min rest interval, were performed for each demand value. We did not feed a measurement value back to the participants, who were divided randomly into two groups, one group beginning the trials with the left arm, and the other with the right.

Thereafter, the participants selected at random the enforcement order of demand values for each arm from the following six MVC patterns: (1) $25 \% \rightarrow$ $50 \% \rightarrow 75 \%$, (2) $25 \% \rightarrow 75 \% \rightarrow 50 \%$, (3) $50 \% \rightarrow 25 \% \rightarrow 75 \%$, (4) $50 \% \rightarrow 75 \% \rightarrow 25 \%$, (5) $75 \% \rightarrow 25 \% \rightarrow 50 \%$, and (6) $75 \% \rightarrow 50 \% \rightarrow 25 \%$. Differences (errors) between demand and exerted values for each trial (25\%,50\%, and 75\% MVC) were calculated. Assuming that a smaller error is superior for accuracy of force exertion, the lesser error of two trials was used as a parameter.

3) Parameters

Presumably, when subjects repeat ten trials for each demand value, errors between demand and exertion values decrease as the trials progress, but they are even fewer with feedback.

We calculated the following: differences (errors) between the demand and exerted values for each trial, a mean error of the first and second trials (the first mean) and the ninth and tenth trials (the last mean), and a change ratio (the first mean/the last mean). In this study, the first and last mean errors and the change rate were used as parameters.

4) Data Analysis

Intra-class correlation coefficient (ICC) for each test was calculated to examine reliability. A two-way ANOVA (demand value $\times$ dominant/non-dominant arms) was used to examine differences among mean errors. When a significant interaction or main effect was found, a Tukey's Honestly Significant Difference (HSD) test was used for a multiple comparison. A t-test was used to examine the difference between the total errors of dominant and non-dominant arms. The level of significance was determined to be 0.05 .

\section{Results}

In the dominant arm, the ICCs of error were 0.94 in 25\% MVC, 0.84 in 50\% MVC, and 0.78 in $75 \%$ MVC; in the non-dominant arm, they were 0.95 in $25 \%$ MVC, 0.87 in 50\% MVC, and 0.96 in 75\% MVC.

Table 1 shows the basic statistics of the errors of elbow flexion strength according to demand values and dominant and non-dominant arms, and results of the two-way ANOVA. Significant interaction was found. Multiple comparison tests showed that an error was greater in 25\% MVC than in 50\% and $75 \%$ MVC for both arms.

Table 2 shows the basic statistics of total error according to dominant and 
Table 1. Basic statistics of the errors of elbow flexion strength according to demand values and dominant and non-dominant arms, and results of the two-way ANOVA.

\begin{tabular}{|c|c|c|c|c|c|c|c|c|c|c|}
\hline & \multicolumn{2}{|c|}{$25 \%$ MVC } & \multicolumn{2}{|c|}{$50 \%$ MVC } & \multicolumn{3}{|c|}{ 75\% MVC } & \multirow{2}{*}{$\begin{array}{c}\begin{array}{c}\text { F-Value } \\
\text { (degree } \\
\text { offreedom) }\end{array} \\
5.96 \times(1.21)\end{array}$} & \multirow{2}{*}{$\begin{array}{c}p \text {-value } \\
\\
0.02\end{array}$} & Post-hoc \\
\hline & Mean & $\mathrm{SD}$ & Mean & SD & Mean & $\mathrm{SD}$ & F1: & & & $\begin{array}{c}\text { Dominant, } \\
\text { Non } \\
\text { dominant; } \\
25 \% \text { MVC > } \\
50 \% \text { MVC, } \\
75 \% \text { MVC }\end{array}$ \\
\hline $\begin{array}{c}\text { Dominant } \\
(\%)\end{array}$ & 16.8 & 13.9 & 6.9 & 7.1 & 5.4 & 5.9 & F2: & $12.36 \times(2.42)$ & 0.00 & \\
\hline $\begin{array}{c}\text { Non } \\
\text { dominant } \\
(\%)\end{array}$ & 19.5 & 17.3 & 11.0 & 7.2 & 7.3 & 12.2 & F3: & $6.65 \times(2.42)$ & 0.00 & \\
\hline
\end{tabular}

$p<0.05, \mathrm{~F} 1$ : demand value, F2, dominant/non-dominant arms, F3: interaction.

Table 2. Basic statistics of total error according to dominant and non-dominant arms and results of the t-test.

\begin{tabular}{|c|c|c|c|c|c|}
\hline \multicolumn{2}{|c|}{ Dominant (\%) } & \multicolumn{2}{|c|}{ Non dominant (\%) } & \multirow[b]{2}{*}{$\mathrm{t}$-value } & \multirow[b]{2}{*}{$p$-value } \\
\hline Mean & $\mathrm{SD}$ & Mean & $\mathrm{SD}$ & & \\
\hline 29.1 & 19.4 & 37.8 & 26.3 & 1.84 & 0.08 \\
\hline
\end{tabular}

non-dominant arms and results of the t-test. No significant difference was found in any demand values.

\section{Discussion}

The ICC showed a higher value than 0.75 in both dominant and non-dominant arms. In short, results confirmed that the subjective force exertion of elbow flexion in both arms had high reliability. According to Kubota et al.'s report (2012), which examined the reliability of controlled force exertion in a handgrip movement, the ICC ranged from 0.69 to 0.83 and did not show a difference between dominant and non-dominant hands, but in this study, the ICC was higher. Presumably, reliability among trials of force exertion tests in this study was high. The present results showed that errors between demand and exertion values in subjective force exertion of elbow flexion were greater in 25\% MVC than in 50\% and 75\% MVC in both arms, and that the accuracy of force exertions differed among demand values. In this study, we did not reveal to the participants their first measured value as outside information. Hence, the participants might have been conscious of when they exerted maximum elbow flexion strength in force exertions for each demand value. Among demand values, 25\% MVC was the least and the furthest from maximum strength, and thus its error might be the greatest. In addition, 75\% MVC is near maximum strength, and $50 \%$ MVC is mid-strength. From the present results of the elbow flexion move- 
ment, persons can more nearly achieve force demand values over 50\% MVC than at 25\% MVC. In addition, Noguchi et al. (2014) reported no significant difference among demand values of $20 \%, 40 \%, 60 \%$, and $80 \%$ MVC in short in accuracy of handgrip exertions, regardless of differences in demand values. Although handgrip movement uses plural small joints, and the innervation ratio of muscle groups of the hand and fingers related to movement is high, elbow flexion movement uses a single large joint, and the innervation ratio of the biceps brachii muscle with its agonist is low (Nagata et al., 1976). Hence, the former muscle groups (handgrip) easily exert strength to adjust to demand values, but the latter muscle (biceps brachii) show difficulty performing minute force exertion. For elbow flexion, 25\% MVC lower than maximum strength, in particular, shows large error; thus, accuracy of force exertion on demand values might also differ.

The errors of each demand value and the total error did not show differences between dominant and non-dominant arms. Furthermore, laterality was not found in the accuracy of elbow flexion force exertions. Kitabayashi et al. (2012) reported that an error between demand (50\% MVC) and exertion values in pinch strength exertion is less in the dominant than in the non-dominant hand. Noguchi et al. (2014) reported that the accuracy of force exertions in $20 \%$ and $40 \%$ MVC showed laterality. On the other hand, Seki and Ohtsuki (1995) found little difference between dominant and non-dominant hands in an error between demand and exertion values in force exertions of handgrip and the abduction movement of fingers. In fact, the laterality of error between demand and exertion values in force exertion of the hand and fingers did not always agree. Ia nerve fibers of muscle spindle contribute to control of strength exertion (Yoshitake et al., 2004), and density of muscle spindle differs according to muscles: finger muscles used to performing movements requiring strong motor skill have high density (Voss, 1971). Hence, they are considered superior in their ability to adjust strength exertion. In contrast, since biceps brachii, the agonist muscle of elbow flexion, is little used for movements requiring motor skill, marked laterality might not occur.

In daily life, we have many opportunities to lift or hold things. Hence, similar to handgrip, maintaining and improving our force-exertion sense about elbow flexion is important. This study's results indicate that, for elbow flexion, enhancing our sense of lesser strength exertion might contribute to total improvement of force-exertion sense.

\section{Conclusion}

The accuracy of force exertion in elbow flexion does not show laterality and is higher in greater demand values (over 50\% MVC) than in lesser values (25\% $\mathrm{MVC}$ ) in both dominant and non-dominant arms.

\section{References}

Bohannon, R. (2003). Grip Strength: A Summary of Studies Comparing Dominant and 
Non Dominant Limb Measurements. Perceptual \& Motor Skills, 96, 728-730. https://doi.org/10.2466/pms.2003.96.3.728

Demura, S., Sato, S., \& Nagasawa, Y. (2009). Re-Examination of Useful Items for Determining Hand Dominance. Medica Italiana Archivio per le Scienze Mediche, 168, 169 177.

Dolcos, F., Rice, H. J., \& Gabeza, R. (2002). Hemispheric Asymmetry and Aging Right Hemisphere Decline or Asymmetry Reduction. Neuroscience \& Biobehavioral Reviews, 26, 819-825. https://doi.org/10.1016/S0149-7634(02)00068-4

Kitabayashi, T., Demura, S., \& Aoki, H. (2013). Differences between Maximum and Submaximum Pinch Strengths in Dominant and Non-Dominant Hands. Medica Italiana Archivio per le Scienze Mediche, 172, 179-184.

Kubota, H., \& Demura, S. (2011). Gender Differences and Laterality in Maximal Handgrip Strength and Controlled Force Exertion in Young Adults. Health, 3, 684-688. https://doi.org/10.4236/health.2011.311115

Kubota, H., Demura, S., \& Kawabata, H. (2012). Laterality and Age-Level Differences between Young Women and Elderly Women in Controlled Force Exertion (CFE). Archives of Gerontology and Geriatrics, 54, e68-e72.

https://doi.org/10.1016/j.archger.2011.06.027

Nagasawa, Y., Demura, S., \& Takahashi, K. (2013). Age Differences between the Controlled Force Exertion Measured by a Computer-Generated Sinusoidal and a Bar Chart Display. Archives of Gerontology and Geriatrics, 57, 86-91.

https://doi.org/10.1016/j.archger.2013.02.002

Nagata, A., Muro, M., \& Kitamoto, H. (1976). Frequency Characteristics in Isotonic Muscular Contractions from Correlation Function and Fourier Transformation of Surface Electromyogram (the Second Report). The Japanese Journal of Physical Fitness and Sports Medicine, 25, 28-36. https://doi.org/10.7600/jspfsm1949.25.28

Noguchi, T., Demura, S., \& Aoki, H. (2009). Superiority of the Dominant and Nondominant Hands in Static Strength and Controlled Force Exertion. Perceptual \& Motor Skills, 109, 339-346. https://doi.org/10.2466/pms.109.2.339-346

Noguchi, T., Demura, S., \& Omoya, M. (2014). Accuracy of Force Exertion in Response to Demanded Forces Based on Subjective Information and Laterality. American Journal of Sports Science and Medicine, 2, 190-193. https://doi.org/10.12691/ajssm-2-5-3

Roy, E. A., Bryden, P., \& Gavill, S. (2003). Hand Differences in Pegboard Performance through Development. Brain and Cognition, 53, 315-317. https://doi.org/10.1016/S0278-2626(03)00133-7

Seki, T., \& Ohtsuki, T. (1995). Reproducibility of Subjectively Graded Voluntary Isometric Muscle Strength in Unilateral and Simultaneous Bilateral Exertion. Ergonomics, 38, 1867-1876. https://doi.org/10.1080/00140139508925234

Voss, H. (1971). Tabulation of the Absolute and Relative Muscular Spindle Numbers in Human Skeletal Musculature. Anatomischer Anzeiger, 129, 562-572.

Yoshitake, Y., Nakamoto, H., \& Ue, H. (2011). Mechanism That Contribute to Differences in Perceived Submaximal Force Production between Young and Old Adults and Effect of Strength Training. Research-Aid Report, 26, 131-141. 
Submit or recommend next manuscript to SCIRP and we will provide best service for you:

Accepting pre-submission inquiries through Email, Facebook, LinkedIn, Twitter, etc. A wide selection of journals (inclusive of 9 subjects, more than 200 journals)

Providing 24-hour high-quality service

User-friendly online submission system

Fair and swift peer-review system

Efficient typesetting and proofreading procedure

Display of the result of downloads and visits, as well as the number of cited articles Maximum dissemination of your research work

Submit your manuscript at: http://papersubmission.scirp.org/

Or contact ape@scirp.org 